\title{
Pre- and Post-harvest Harpin Treatments of Apples Induce Resistance to Blue Mold
}

Guy de Capdeville, Embrapa Recursos Genéticos e Biotecnologia, Brasília, DF, 70770-900, Brazil; Steven V. Beer, Department of Plant Pathology, and Christopher B. Watkins, Department of Horticulture, Cornell University, Ithaca, NY 14853; Charles L. Wilson, USDA-ARS, Appalachian Fruit Research Station, Kearneysville, WV 25430; and Luís O. Tedeschi, Department of Animal Science, and James R. Aist, Department of Plant Pathology, Cornell University

\begin{abstract}
de Capdeville, G., Beer, S. V., Watkins, C. B., Wilson, C. L., Tedeschi, L. O., and Aist, J. R. 2003. Pre- and post-harvest harpin treatments of apples induce resistance to blue mold. Plant Dis. 87:39-44.

Harpin was studied for its ability to induce resistance in apple fruit to blue mold caused by Penicillium expansum after harvest. Red Delicious fruit were harvested and sprayed with harpin at $0,40,80$, and $160 \mathrm{mg} / \mathrm{liter}$ applied as a commercial formulation. At 48, 96, and $144 \mathrm{~h}$ after treatment, fruit were wound inoculated with spore suspensions of $P$. expansum at $10^{3}, 5 \times 10^{3}$, or $10^{4}$ spores $/ \mathrm{ml}$. The diameters of the resulting lesions were directly proportional to the inoculum concentration. Fewer fruit treated with harpin became infected relative to the controls, and disease progress was considerably reduced. In a second experiment, apple trees of the cultivars McIntosh, Empire, and Red Delicious were sprayed with different concentrations of harpin 8 or 4 days before harvest. Fruit were harvested, wounded, inoculated with the fungus, and stored in a commercial cold room. Fewer fruit treated with harpin became infected compared with the controls. Greater control resulted from the higher concentrations of harpin, but no difference in control occurred as a function of interval between the spray time and harvest. Spraying apple trees with harpin a few days before harvest is a promising strategy for reducing blue mold decay in storage.
\end{abstract}

Additional keywords: control, disease, fungus, fruit, Malus domestica

Blue mold, caused by Penicillium expansum Link, is an important postharvest disease of apple and is responsible for most losses that occur in most commercial storage rooms $(15,17)$. Depending on the cultivar, infections by this fungus may be initiated through wounds or through the stems $(13,15)$. The control of blue mold has been based on avoiding damage during harvest and processing, sanitation, use of controlled atmosphere storage, and control

Corresponding author: J. R. Aist

E-mail address: jra2@cornell.edu

This research was supported mostly by the Cornell Agricultural Experiment Station federal formula funds, Project No. NYC-153410, and in part by an Arthur Boller Research Grant, both received from Cooperative State Research, Education and Extension Service, United States Department of Agriculture. G. de Capdeville was supported by the Conselho Nacional de Desenvolvimento Científico e Tecnológico (CNPq) during the completion of his Ph.D. program at Cornell University.

Any opinions, findings, conclusions, or recommendations expressed in this publication are those of the authors and do not reflect the view of the United States Department of Agriculture.

Accepted for publication 16 August 2002.

Publication no. D-2002-1028-03R

(C) 2003 The American Phytopathological Society of temperature and relative humidity (RH) (15). However, the most used and effective strategy is the postharvest treatment of apples with fungicides such as thiabendazoles, sometimes combined with widespectrum fungicides (12). Because of recent concerns with fungicide toxicity, development of fungicide resistance by pathogens, and potential harmful effects on the environment and human health that some of these chemicals may have, new strategies for control of postharvest diseases have been proposed (19). Thus, because of the necessity to reduce losses during the postharvest phase while reducing the use of fungicides, new alternative control compounds such as chitosan and harpin have been evaluated as promising alternatives in controlling postharvest diseases by inducing resistance in fruit $(4,5,7,8)$.

Harpin is an acidic, heat-stable, glycinerich, 44-kDa protein, encoded by the $h r p N$ gene of the bacterium Erwinia amylovora. It is the first known bacterial product able to elicit the hypersensitive response (HR) in plants $(1,7,11)$. It also is known to elicit systemic acquired resistance (SAR) in tobacco and Arabidopsis spp. (7) and to induce resistance to blue mold in harvested Red Delicious apples $(3,5)$. Previous studies have shown that harpin triggers a variety of cellular responses, such as activation of active oxygen species and cell membrane depolarization, which are known to be involved in resistance response mechanisms of systemic resistance $(6,7)$. Harpin has been produced commercially as "Messenger", which is currently being suggested for the control of viral and fungal diseases, as well as a plant growth enhancer and a controller of selected insect populations $(18,20)$. The main goals of these studies were to evaluate the ability of harpin to induce resistance to blue mold by treating Red Delicious apple fruit after harvest, and to evaluate the effect of preharvest treatments of three different cultivars on blue mold during cold storage.

\section{MATERIALS AND METHODS}

Inoculum preparation. An isolate (USCU1) of Penicillium expansum Link kept in the United States Department of Agriculture (USDA) Agricultural Fruit Research Station collection (Kearneysville, WV) was used as the source of inoculum for the experiments. The pathogenicity of the isolate was checked by inoculating Red Delicious apple fruit (Malus domestica Borkh.). From lesions formed in those inoculated fruit, pieces of tissue were removed from the edge of the lesions, immersed in $70 \%$ ethanol for $1 \mathrm{~min}$, transferred to a solution of $1 \%$ sodium hypochlorite for $1 \mathrm{~min}$, washed three times for $2 \mathrm{~min}$ each in sterile distilled water, blotted on sterile filter paper, and plated on potato dextrose agar (PDA) medium amended with $0.1 \%$ streptomycin. The plates were placed in a growth chamber at $24^{\circ} \mathrm{C}$ and, after colonies were formed, disks of mycelium were removed from the edge of the colony and transferred to assay tubes containing PDA plus $0.1 \%$ streptomycin, allowed to grow for 3 days at $24^{\circ} \mathrm{C}$, and then stored in the refrigerator at $5^{\circ} \mathrm{C}$. These stock cultures were tested for pathogenicity every 4 months. The stocks were used for generating new, 10-day-old colonies on PDA plus $0.1 \%$ streptomycin from which spores were collected in sterile water amended with $0.01 \%$ Tween 20 . The final concentration of the spore suspension to be used was adjusted using a hemacytometer.

Postharvest treatment. Red Delicious apple fruit were harvested at the Cornell University Orchard at harvest dates chosen 
as representative of the harvest window for the cultivar (2) during the apple season of 1999. The harvested fruit were immediately taken to a controlled environment chamber at $24^{\circ} \mathrm{C}$ and $80 \% \mathrm{RH}$ and, after acclimatizing for $2 \mathrm{~h}$, they were sprayed with an aqueous solution of harpin at 0,40 , 80 , or $160 \mathrm{mg} / \mathrm{liter}(162$ fruit per concentration). For all treatments in this study, harpin was applied as a commercial formulation (Messenger). The harpin solution was allowed to dry on the fruit surface and, at 48, 96, or $144 \mathrm{~h}$ after treatment, fruit were wounded and inoculated with spore suspensions of $P$. expansum at $10^{3}, 5$ $\times 10^{3}$, or $10^{4}$ spores $/ \mathrm{ml}$ (18 replicate fruit per combination of inoculation time, harpin concentration, and spore concentra-
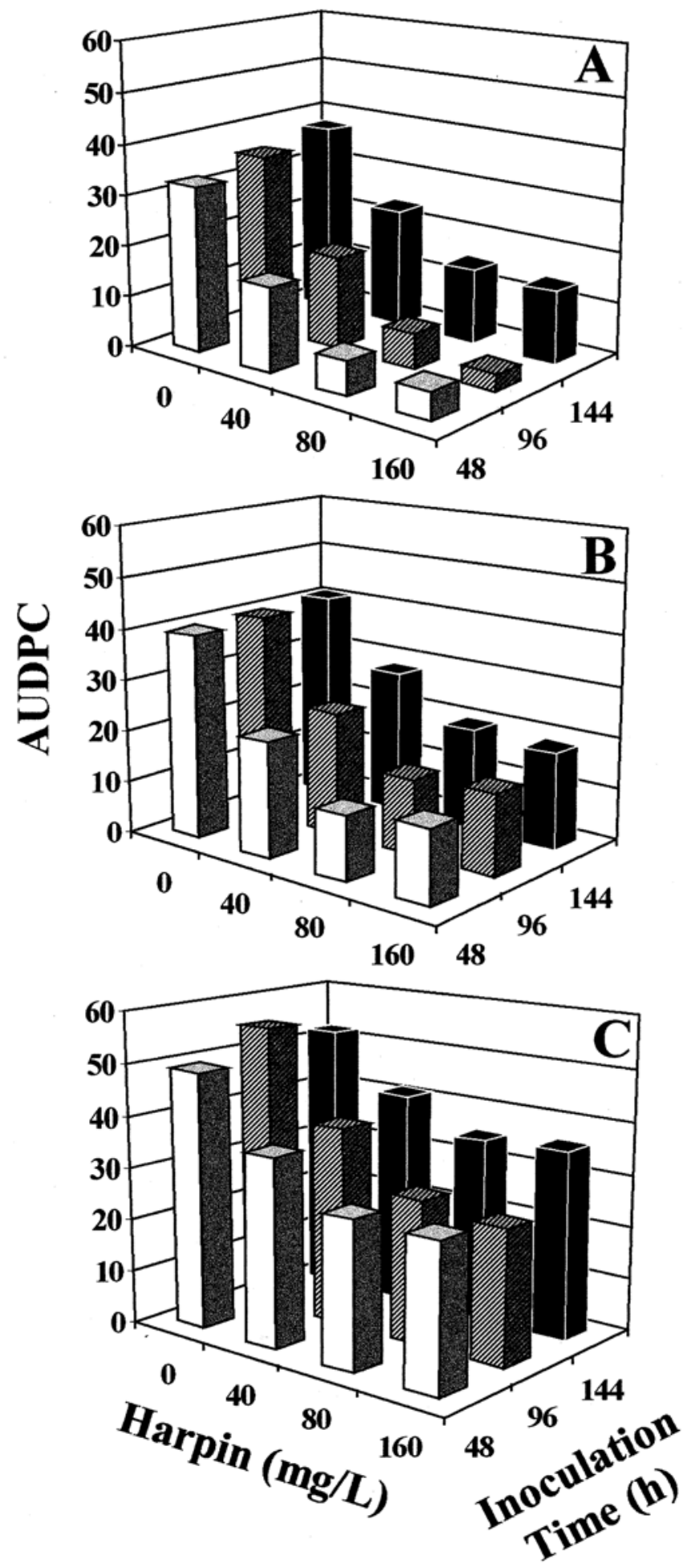

Fig. 1. Area under the disease progress curve (AUDPC) of blue mold of Red Delicious apples treated with four concentrations of harpin and inoculated with Penicillium expansum at 48, 96, and $144 \mathrm{~h}$ after treatment. Apples were inoculated with $P$. expansum at A, $10^{3}, \mathbf{B}, 5 \times 10^{3}$, and $\mathbf{C}, 10^{4} \mathrm{spores} / \mathrm{ml}$.

tion). Development of disease was evaluated every 2 days for a period of 12 days by measuring the diameter of lesions formed. These measurements were used to calculate the area under the disease progress curve (AUDPC) using the equation proposed by Shaner and Finney (14): AUDPC $=\Sigma\left[\left(y_{i}+y_{i+1}\right) / 2 \times\left(t_{i+1}-t_{i}\right)\right]$, where $y_{\mathrm{i}}$ is the diameter of a lesion at time $t_{i}$, in days, and $y_{i+1}$ is the diameter of the lesion at time $t_{i+1}$. This experiment was repeated once, and both times the growth rates of the lesions formed for each treatment also was calculated as additional criteria for quantifying resistance.

Preharvest treatment. This experiment was conducted three times, each time with a different cultivar, during the months of September and October 2000. Mature trees of Roger McIntosh grafted on rootstock M/9, Empire grafted on rootstock MM/111, and Red Chief Red Delicious grafted on rootstock M9/111 were used for the experiments. The harvest dates, based on the progression of starch indices, were 21 September, 3 October, and 11 October 2000 for cvs. McIntosh, Empire, and Red Delicious, respectively (2). The trees were sprayed 8 or 4 days before harvest with solutions of harpin at 20,40, and 80 $\mathrm{mg} / \mathrm{liter}$, and with two control treatments: (i) a $40 \mathrm{mg} /$ liter water solution made of all basic components of the commercial formulation except the active ingredient harpin and (ii) water (universal control). A total of 3 replicate trees per treatment and spray time (30 trees per cultivar) were sprayed to run off with the solutions or water using a compressed gas-powered tank sprayer. Approximately 3.6 liters was applied to each tree, making sure that all leaves and fruit surfaces were completely wetted with the solutions. No other sprays had been applied to the trees within a month before harvest.

Effect of preharvest treatment with harpin on blue mold decay after harvest. At the harvest date ( 8 and 4 days after spraying) 40 fruit per tree were harvested, and a wound $2 \mathrm{~mm}$ deep and $2 \mathrm{~mm}$ in diameter was made in each of the fruit. Half of the wounded fruit was inoculated by flooding each wound with a $20-\mu \mathrm{l}$ drop of a spore suspension of $P$. expansum at a concentration of $5 \times 10^{3}$ spores/ml (approximately 100 spores per wound). The other half of the wounded fruit was not inoculated, to evaluate the effect of the treatments on infections originating from inoculum resident in the storage environment. The inoculated and uninoculated fruit were packed on trays in cardboard boxes and stored immediately after inoculation in a cold room at $0.5^{\circ} \mathrm{C}$ with normal atmosphere for 120 days. Four evaluations of the numbers of infected and noninfected fruit were performed (at 30, 60,90 , and 120 days) during the time the fruit were stored. Just after the fourth evaluation, the boxes containing the re- 
maining nondiseased fruit were removed from the storage room and left at $20^{\circ} \mathrm{C}$ for 7 days, when a fifth evaluation was performed to assess any possible latent infections that might have been impaired by the storage environment. During the evaluations, fruit showing symptoms of blue mold were discarded, and the number of uninfected fruit as well as infected fruit was recorded and used for the statistical analysis.

Statistical analyses. All data were analyzed using the SAS software (version 8e; SAS Institute, Cary, NC). The data of the postharvest experiment were analyzed as a 4-by-3-by-3 factorial with 18 fruit per treatment, using PROC GLM according to the model described below (9). The least square mean (LSMeans) was used to perform the multiple comparison of the means. $Y_{i j k l}=\mu+\alpha_{i}+\beta_{j}+\gamma_{k}+(\alpha \beta)_{i j}+$ $(\alpha \gamma)_{i k}+(\beta \gamma)_{j k}+(\alpha \beta \gamma)_{i j k}+e_{i j k l}$, where $\alpha_{i}=$ treatment $(0,40,80$, and $160 \mathrm{mg} / \mathrm{liter}) ; \beta_{j}$ $=$ inoculation time $(48,96$, and $144 \mathrm{~h}) ; \gamma_{k}=$ inoculum concentration $\left(10^{3}, 5 \times 10^{3}\right.$, and $10^{4}$ spores $\left./ \mathrm{ml}\right) ;(\alpha \beta)_{i j}=$ interaction between $\alpha_{i}$ and $\beta_{j} ;(\alpha \gamma)_{i k}=$ interaction between $\alpha_{i}$ and $\gamma_{k}$; $(\beta \gamma)_{j k}=$ interaction between $\beta_{j}$ and $\gamma_{k} ;(\alpha \beta \gamma)_{i j k}=$ interaction between $\alpha_{i}, \beta_{j}$, and $\gamma_{k}$; and $e_{i j k l}=$ random error; for $i$ varying from 1 to 4 (treatment); $j$ from 1 to 3 (inoculation time); and $k$ from 1 to 3 (inoculum concentration).

Additionally, a regression analysis using PROC GLM was performed within each inoculum concentration using the model below (9). The interaction terms were removed from the model if not significant at $\alpha=0.05$. The $R^{2}$ reported are the regression of the least square mean of the desired comparison. $Y_{i j k}=\kappa_{0}+\kappa_{1} \alpha_{i}+\kappa_{2} \gamma_{j}+$ $\kappa_{3}(\alpha \gamma)_{i j}+\kappa_{1} \alpha_{i}^{2}+\kappa_{2} \gamma_{j}^{2}+\kappa_{3}(\alpha \gamma)_{i j}^{2}+\varepsilon_{i j k}$, where $\kappa$ is the regression coefficient, $\alpha_{i}$ is the treatment effect $(0,40,80$, and 160 $\mathrm{mg} / \mathrm{liter}), \gamma_{k}$ is the inoculum concentration effect $\left(10^{3}, 5 \times 10^{3}\right.$, and $10^{4}$ spores $\left./ \mathrm{ml}\right)$, and $\varepsilon_{i j k}$ is the random error.

For the pre-harvest experiment, the data for percentage of diseased fruit (transformed to arcsine square root) within each cultivar (McIntosh, Empire, and Red Delicious) were analyzed as a split-plot design (9) using the PROC GLM of SAS. The following statistical model was used: $Y_{i j k l m}$ $=\mu+\alpha_{i}+\beta_{j}+(\alpha \beta)_{i j}+\delta_{k l(i j)}+\gamma_{m}+(\beta \gamma)_{j m}+$ $(\alpha \gamma)_{i m}+(\alpha \beta \gamma)_{i j m}+e_{i j k l m}$, where $\alpha_{i}=$ treatment (harpin at $0,20,40$, and 80 $\mathrm{mg} / \mathrm{liter}$ ); $\beta_{j}=$ spray time ( 4 and 8 days before harvest); $(\alpha \beta)_{i j}=$ interaction between $\alpha_{i}$ and $\beta_{j} ; \delta_{l k(i j)}=$ random error calculated as fruit (16) and tree (3) interaction within treatment and spray time interaction to test $\alpha_{i}, \beta_{j}$, and $(\alpha \beta)_{i j}$ effects; $\gamma_{m}=$ days in storage, 120 and 127 days, $(\alpha \gamma)_{i m}=$ interaction between $\alpha_{i}$ and $\gamma_{m} ;(\beta \gamma)_{j m}=$ interaction between $\beta_{j}$ and $\gamma_{m} ;(\alpha \beta \gamma)_{i j m}=$ interaction between $\alpha_{i}, \beta_{j}$, and $\gamma_{m}$, and $e_{i j k l m}$ $=$ random error; for $i$ varying from 1 to 4 (treatment), $j$ from 1 to 2 (spray time), $k$ from 1 to 20 (fruit per tree), $l$ from 1 to 3
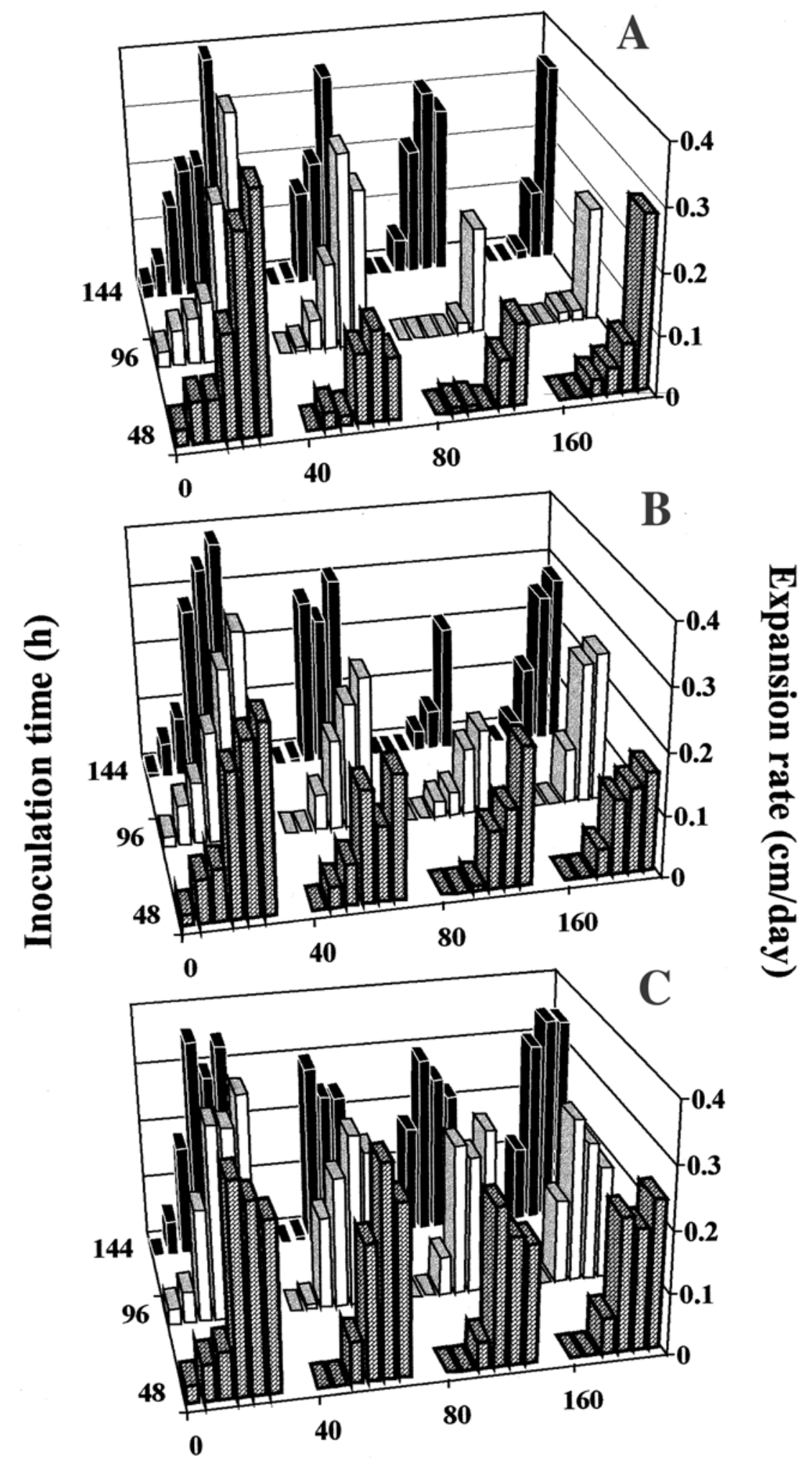

Harpin (mg/L)

Fig. 2. Expansion rate of lesions of blue mold on Red Delicious apples treated with four concentrations of harpin and inoculated with Penicillium expansum at A, $10^{3}, \mathbf{B}, 5 \times 10^{3}$, or $\mathbf{C}, 10^{4}$ spores $/ \mathrm{ml}$. Each bar in the graphics corresponds to a rate calculated by subtracting the value of the diameter of a lesion of one evaluation from the diameter of the immediately subsequent evaluation and then, dividing the resulting value by two (days between assessments) to give the final rate in centimeters per day. 
(trees), and $m$ from 1 to 3 (days in storage).

All mean comparisons were obtained by the LSMeans procedure. Linear, quadratic, and cubic polynomial analyses were performed by orthogonal contrasts to identify a statistical trend. All the graphics presented were constructed using back-transformed means. The $R^{2}$ reported are the regression of the least square mean of the desired comparison.

The statistical model and analyses used to compare the two control treatments (water control and messenger control without harpin) used in this work were similar to those described above, varying only in the number of treatments (two instead of four).

Outliers were identified using the plot of studentized residue against the predicted (SAS Institute, Inc.). The plot of the studentized residue against the effects studied was analyzed to test the assumption of identical variance (9).

\section{RESULTS}

Postharvest treatment. Although similar responses were obtained both times the experiment was conducted, only the results of the first trial are presented here, where postharvest treatment of Red Delicious fruit with harpin reduced the AUDPC
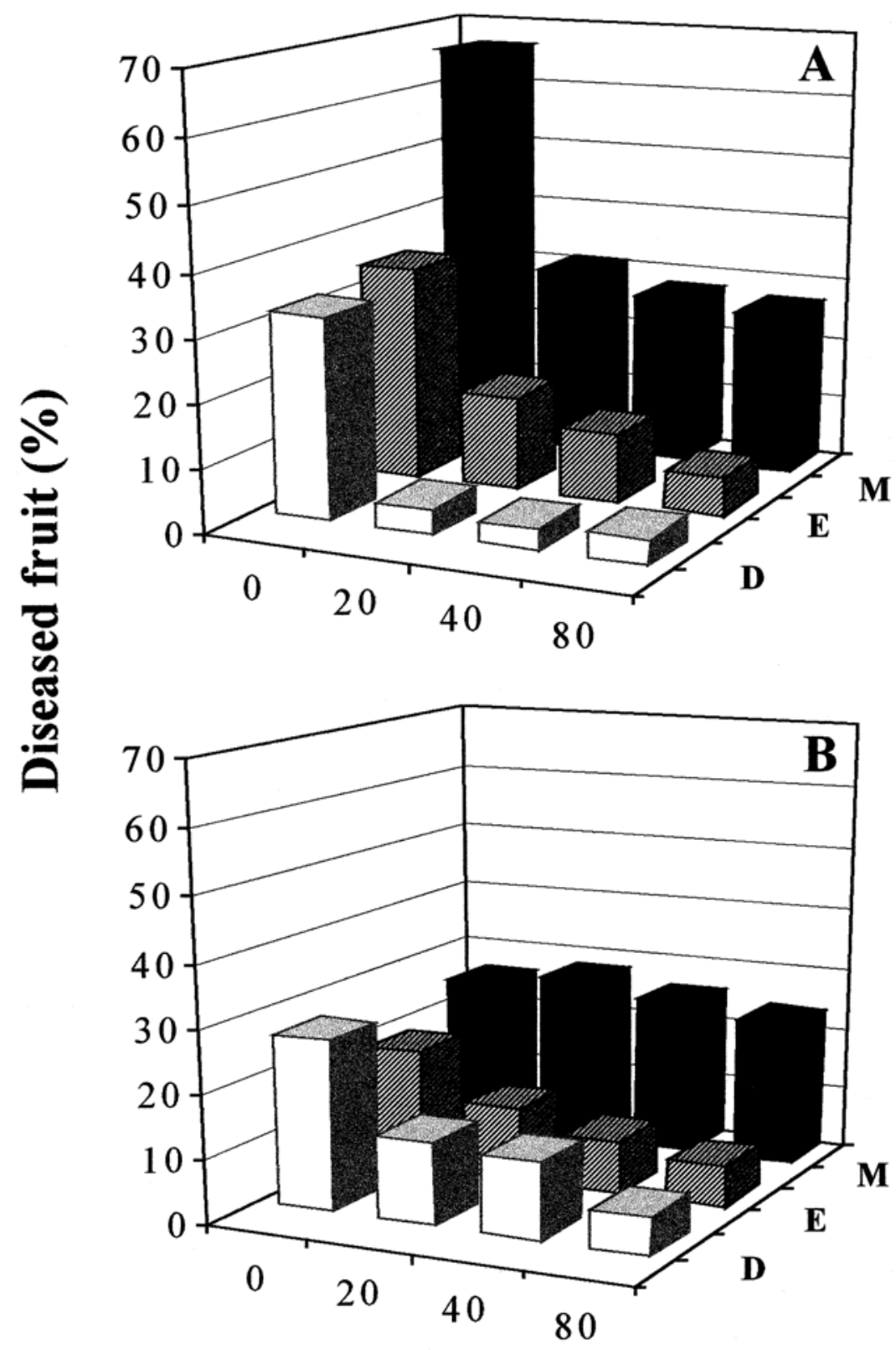

Harpin (mg/L)

Fig. 3. Percentage of McIntosh (M), Empire (E), and Red Delicious (D) apples showing symptoms of natural infections by Penicillium expansum originating after a period of storage of $\mathbf{A}, 120$ days in air at $0.5^{\circ} \mathrm{C}$ or $\mathbf{B}, 120$ days at $0.5^{\circ} \mathrm{C}$ plus 7 days at $20^{\circ} \mathrm{C}$. Harpin was applied to the trees before harvest.

when the fruit were treated with all harpin concentrations, independently of the concentration of spores used or time of inoculation (Fig. 1A, B, and C). For all inoculum concentrations, reduction of AUDPC was greater $(P<0.05)$ in the treatments with 80 and 160 compared with 0 and 40 $\mathrm{mg} /$ liter. However, the effect of harpin concentration was more pronounced on fruit inoculated with a concentration of $10^{3}$ spores $/ \mathrm{ml}\left(R^{2}=0.87, P<0.0001\right)$, followed by the concentrations of $5 \times 10^{3}\left(R^{2}\right.$ $=0.82, P<0.0024)$ and $10^{4}$ spores $/ \mathrm{ml}\left(R^{2}\right.$ $=0.82, P<0.0001)$, respectively. Inoculating fruit 48 or $96 \mathrm{~h}$ following treatment resulted in greater control of disease compared with $144 \mathrm{~h}$. Analyzing the expansion rate of the lesions, it became clear that the treatments significantly delayed the development of the lesions, especially in those with the two lowest inoculum concentrations (Fig. 2). For fruit inoculated $96 \mathrm{~h}$ after treatment with $10^{3}$ spores $/ \mathrm{ml}$, the concentrations of 80 and $160 \mathrm{mg} /$ liter resulted in a delay of 8 and 6 days, respectively, in the appearance of a lesion relative to the controls, in which lesions were seen at the first evaluation, 2 days after inoculation (Fig. 2A). These delays were considerably reduced when the concentration of spores was increased to $5 \times 10^{3}$ and $10^{4}$, respectively, (Fig. 2B and C). It is clear also that the concentration of inoculum is directly proportional to the time of appearance and expansion rate of lesions (Fig. 2).

Postharvest disease assessment. For the three cultivars studied, treatment with harpin before harvest reduced the percentage of infected fruit that developed after harvest. Overall, the percentage of infected fruit was inversely proportional to harpin concentration in both inoculated and noninoculated assays (Figs. 3 and 4). The data for the noninoculated fruit indicated also that about $70 \%$ of the controls for McIntosh became infected while only about $30 \%$ of the harpin-treated fruit of this cultivar were diseased $(P<0.0001)$ after 4 months of storage. Empire fruit developed lesions in $32 \%$ of the controls and in about 5 to $10 \%$ of the harpin-treated fruit. Red Delicious fruit appeared less susceptible, with $30 \%$ of the controls and about $4 \%$ of the harpin-treated fruit infected after 120 days. Not much difference was observed between the analysis of Empire and Red Delicious cultivars. However, the effect of harpin concentration seemed to be somewhat more intense on Red Delicious, because even the smallest concentration was as effective as the highest concentration in controlling the disease $\left(R^{2}=0.72, P<\right.$ $0.0002)$. The orthogonal polynomial indicated that a linear effect of harpin concentration on Empire fruit varied significantly $\left(R^{2}\right.$ $=0.78, P<0.0001$ ), in which a harpin concentration of $80 \mathrm{mg} / \mathrm{liter}$ was most effective in reducing the percentage of infected fruit $(P<0.05$; Fig. 3A). 
A significant linear effect of harpin concentration also was detected on fruit that remained uninfected after 4 months of storage and were held at $20^{\circ} \mathrm{C}$ for 7 days, for Empire $\left(R^{2}=0.88, P=0.0002\right)$ and Red Delicious $\left(R^{2}=0.92, P<0.0001\right)$, but not for McIntosh (Fig. 3B). Overall, McIntosh fruit were more susceptible to natural infections and exhibited less reduction in infection from treatment with harpin than did the other cultivars.

The data from the inoculated fruit showed that a significant linear effect of harpin concentration occurred when fruit were stored for 120 days for the cultivars McIntosh $\left(R^{2}=0.74, P=0.0004\right)$, Empire $\left(R^{2}=0.75, P<0.0001\right)$, and Red Delicious $\left(R^{2}=0.85, P<0.0002\right)$. Significant differences were not detected between McIntosh and Empire, but both cultivars differed considerably from Red Delicious, even for the control fruit (Fig. 4A). The effect of harpin concentration also was shown with the nondiseased fruit that were removed from storage and held at $20^{\circ} \mathrm{C}$ for 7 days. Under this condition, Empire and Red Delicious fruit responded to the treatments very similarly, where the percentage of infected fruit decreased with increasing harpin concentration (Fig. 4B). The percentage of infected McIntosh fruit also was reduced by the treatments $(P=0.032)$, but a concentration effect was less evident for McIntosh than for the other cultivars.

No significant differences between the two control treatments were detected $(P=$ 0.1487).

\section{DISCUSSION}

Harpin induced resistance in apple fruit against blue mold when it was applied after harvest. The level of resistance depended on harpin concentration, inoculum concentration, and interval between treatment and inoculation. When applied before harvest, harpin also effectively reduced the percentage of diseased fruit after a storage period of 120 days in all cultivars studied.

Although more work needs to be done to evaluate the effect of the treatments on the same cultivars grown under different seasons and conditions, and on different cultivars, we were able to establish that the three cultivars studied responded differently to the treatments depending on whether or not the fruit were inoculated. Overall, Red Delicious fruit had the lowest percentage of disease among the controls and harpin-treated fruit. McIntosh had the highest percentage of diseased fruit while Empire fruit showed an intermediate resistance response, being similar to Red Delicious when fruit were not inoculated and similar to McIntosh when the fruit were inoculated. The effectiveness of the treatments was observed even after cold storage, when the remaining non-infected fruit were placed at $20^{\circ} \mathrm{C}$ for 7 days.

Harpin has been shown to induce HR and SAR in tobacco, Arabidopsis spp., and other plants (7). Dong et al. (7) have demonstrated that harpin induces the expression of pathogenesis-related (PR) genes as well as other early response activators, such as active oxygen species, and that these resistance responses are systemic. They also pointed out that resistance response mediators are activated in as little as a few minutes and may last for hours or even days. We suspect that the expression of PR genes may be one of the possible mechanisms by which harpin acts on harvested apples. Indeed, preliminary studies have shown that the inoculation of apple leaves with E. amylovora triggers the ex- pression of PR genes over time (J. M. Bonsera and S. V. Beer, unpublished data). Because of the systemic nature of the induced resistance response elicited by harpin in tobacco, Arabidopsis spp, and other plants (7), one may speculate that spraying apple trees with harpin before harvest may increase the transport to and accumulation or synthesis of resistance "factors" in the fruit, leading to an increase in fruit resistance. This possibility is supported by the data on the concentration of harpin needed to achieve the same level of resistance in Red Delicious fruit treated before or after harvest. In this respect, fruit
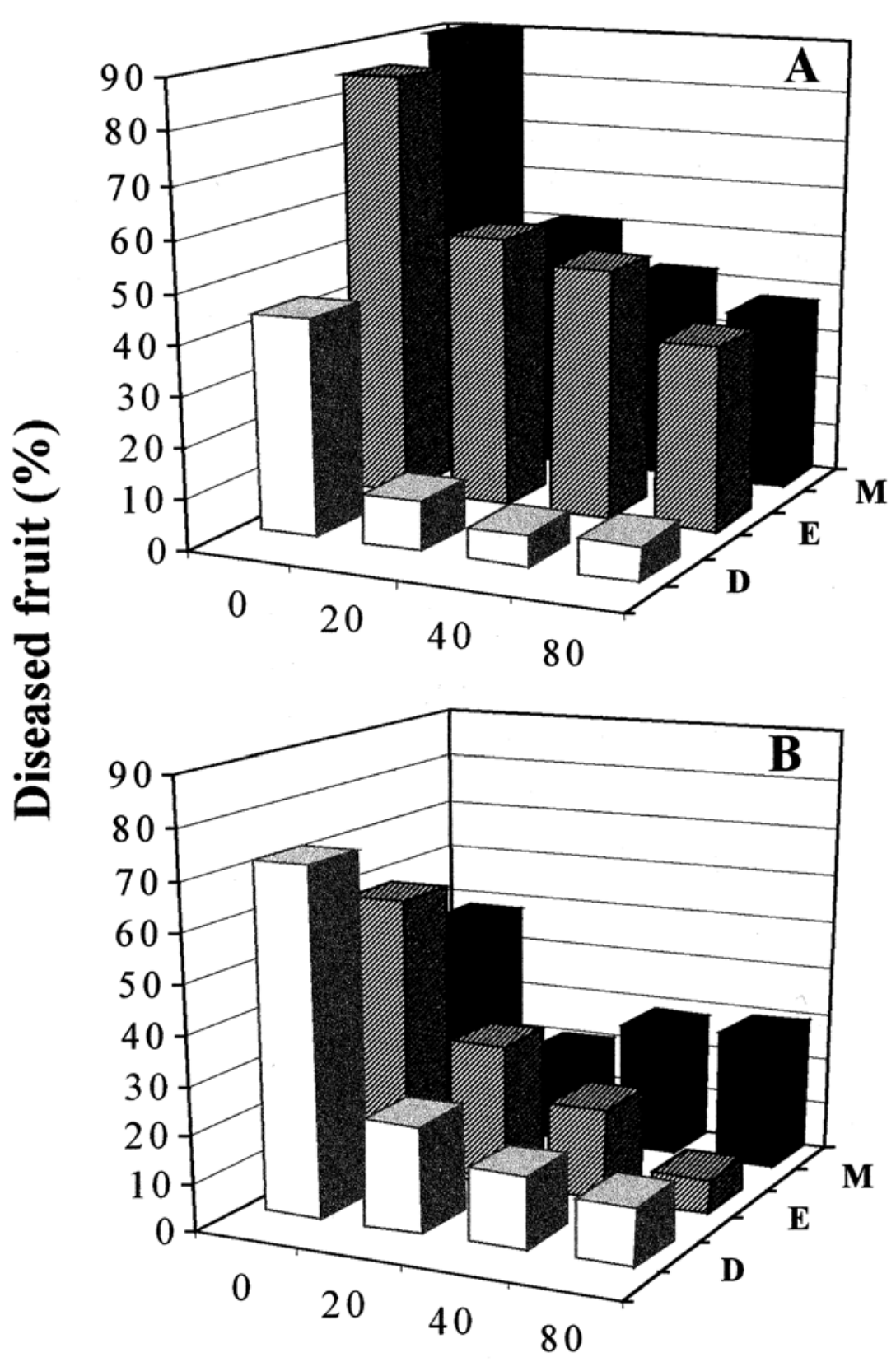

\section{Harpin (mg/L)}

Fig. 4. Percentage of McIntosh (M), Empire (E), and Red Delicious (D) apples showing symptoms of blue mold after inoculation with Penicillium expansum and storage for A, 120 days in air at $0.5^{\circ} \mathrm{C}$ or B, 120 days at $0.5^{\circ} \mathrm{C}$ plus 7 days at $20^{\circ} \mathrm{C}$. Harpin was applied to the trees before harvest. 
treated before harvest with concentrations as low as $20 \mathrm{mg} / \mathrm{liter}$ of harpin responded with levels of control similar to those treated after harvest with concentrations above $40 \mathrm{mg} /$ liter of harpin. This differential response to harpin concentration is, indeed, a good indication that some kind of systemic enhancement of resistance takes place when fruit are treated while still attached to the plant.

A parallel cytological study recently concluded and currently in preparation for publication has shown that harpin induces the accumulation of putative tannins in large vacuoles in epidermal and hypodermal cells of harpin-treated Red Delicious fruit (4). Lees et al. (10) reported that condensed tannin frequently is deposited in the vacuoles of hypodermal cells in different cultivars of apples and that, among the cultivars studied, Red Delicious fruit showed the highest content of tannin. They also concluded that tannin was only present in the hypodermis, not in epidermal cells. We found that accumulation of tannin occurred in about the same proportion in both layers of cells, indicating that treatment with harpin induced accumulation also in the epidermal cells. In addition, these cytological studies have shown that harpin induces some structural changes in the cell wall, such as the accumulation of wall-like appositions. These changes took place inside the cells and in the intercellular spaces of epidermal, hypodermal, and parenchyma cells, and may be related to disease resistance (G. de Capdeville, S. V. Beer, C. L. Wilson, and J. R. Aist, unpublished). It is possible that resistance mechanisms triggered by harpin during the preharvest treatments of the apples remained active during the long storage period because low temperature reduced cell metabolism, consequently reducing the degradation of resistance factors produced in the cells. This possibility is supported by the fact that symptomless harpin-treated fruit removed from storage and held at $20^{\circ} \mathrm{C}$ for 7 days had fewer infected fruit at the final evaluation than did the controls.

The resistance to blue mold in cold storage varied among the three cultivars studied. Red Delicious clearly was less susceptible than were the fruit of the other two cultivars at low storage temperature. However, after 4 months in cold storage and incubation at room temperature, the three cultivars sustained similar levels of disease. Although it is important to repeat these experiments with different cultivars and under different conditions, differences in the degree of resistance among cultivars of apples to postharvest infections by different pathogens have been reported previously (16). Spotts et al. (16) concluded that the relative cultivar resistance to one specific pathogen was not necessarily related to its relative resistance to other pathogens.

Further work needs to be done to determine the utility of harpin in the field under commercial conditions, and to evaluate the effect of harpin on additional cultivars and on the same cultivars grown in different regions. The effect of harpin treatment on other postharvest pathogens also should be determined. Nevertheless, the results presented here demonstrate that harpin has the ability to induce resistance and to control blue mold of apple when applied to the fruit after or, preferably, before harvest. The use of harpin in an integrated pest management strategy may help to reduce losses caused by postharvest diseases, as well as further reduce the potential harmful effect of the use of fungicides to control postharvest diseases.

\section{ACKNOWLEDGMENTS}

We thank S. J. Schwager of the Department of Biometrics, Cornell University, for his help with the statistical analyses.

\section{LITERATURE CITED}

1. Baker, C. J., Orlandi, E. W., and Mock, N. M. 1993. Harpin, an elicitor of the hypersensitive response in tobacco caused by Erwinia amylovora, elicits active oxygen production in suspension cells. Plant Physiol. 102:1341-1344.

2. Blanpied, G. D., and Silsby, K.. 1992. Predicting harvest date windows for apples. Info. Bull. 221. Cornell University, Ithaca, NY.

3. de Capdeville, G., Beer, S .V., Watkins, C. B., Wilson, C. L., and Aist, J. R. 2001. Harpin-induced resistance for the control of blue mold of apples. (Abstr.) Phytopathology 91:S166.

4. de Capdeville, G., Beer, S. V., Wilson, C. L., and Aist, J. R.. 2001. Mechanisms of harpininduced resistance against blue mold of apples. (Abstr.) Phytopathology 91:S21.

5. de Capdeville, G.., Beer, S. V., Wilson, C. L., and Aist, J. R. 2002. Alternative disease control agents induce resistance to blue mold in harvested 'Red Delicious' apple fruit. Phytopathology 92:900-908.

6. Delaney, T. P. 1997. Genetic dissection of acquired resistance to disease. Plant Physiol.
113:5-12.

7. Dong, H., Delaney, T. P., Bauer, D. W., and Beer, S. V. 1999. Harpin induces disease resistance in Arabidopsis through the systemic acquired resistance pathway mediated by salicylic acid and the NIM1 gene. Plant J. 20:207-215.

8. El Ghaouth, A. 1994. Manipulation of defense systems with elicitors to control postharvest diseases. Pages 153-167 in: Biological Control of Postharvest Diseases: Theory and Practice. C. L. Wilson and M. E. Wisniewski, eds. CRC Press, Inc., Boca Raton, FL.

9. Kuehl, R. O. 2000. Design of Experiments: Statistical Principles of Research Design and Analysis. 2nd ed. Duxbury, Pacific Grove, CA.

10. Lees. G. L., Wall, K. M., Beveridge, T. H. and Suttill, N. H. 1995. Localization of condensed tannins in apple fruit peel, pulp, and seeds. Can. J. Bot. 73:1897-1904.

11. Mullin, P., Wang, J. S., Qiu, D., and Wei, Z. M. 1998. Disease control and growth enhancement effects of harpin on tobacco. (Abstr.) Phytopathology 88:S65.

12. Prusky, D., Bazak, M., and Ben-Arie, R 1985. Development, persistence, survival, and strategies for control of thiabendazoleresistant strains of Penicillium expansum on pome fruit. Phytopathology 75:877-882.

13. Rosenberger, D. A., Ahlers, C. A., and Meyer, F. W. 2001. Penicillium expansum invades Empire apples through stems during long term controlled atmosphere storage. Am Phytopathol. Soc. On-line publication /P2001-0030-NEA.

14. Shaner, G., and Finney, R. E. 1977. The effect of nitrogen fertilization on the expression of slow mildewing resistance in Knox wheat. Phytopathology 67:1051-1056.

15. Snowdon, A. L. 1990. Color Atlas of PostHarvest Diseases and Disorders of Fruit and Vegetables. Vol. 1. CRC Press, Inc. Boca Raton, FL.

16. Sommer, N. F., Fortlage, R. J., and Edwards, D. C. 1992. Postharvest diseases of selected commodities. Pages 117-160 in: Postharvest of Horticultural Crops. A. A. Kader, ed UCLA-DANR Communication ServicesPublications, Oakland, CA.

17. Spotts, R. A., Cervantes, L. A., and Mielke, E. A. 1999. Variability in postharvest decay among apple cultivars. Plant Dis. 83:10511054

18. Wei, Z. M., Qiu, D., Kropp, M. J., and Schading, R. L. 1998. Harpin, an HR elicitor, activates both defense and growth systems in many commercially important crops. (Abstr.) Phytopathology 88:S96.

19. Wilson, C. L., El, G. A., Chalutz, E., Droby, S., Stevens, C., Lu, J. Y., Khan, V., and Arul, J. 1994. Potential of induced resistance to control postharvest diseases of fruit and vegetables. Plant Dis. 78:837-844.

20. Zitter, T. A., and Beer, S. V. 1998. Harpin for insect control. (Abstr.) Phytopathology 88:S104. 